Pourquoi moi ? L'expérience des discriminations, François Dubet, Cousin Olivier Cousin, Eric Macé, Sandrine Rui

Seuil, 2013

Jean-Pierre Véran

CpenEdition

Journals

Édition électronique

URL : http://journals.openedition.org/ries/3585

DOI : 10.4000/ries.3585

ISSN : 2261-4265

Éditeur

Centre international d'études pédagogiques

Édition imprimée

Date de publication : 1 décembre 2013

Pagination : 26-28

ISBN : 978-2-85420-601-2

ISSN : $1254-4590$

Référence électronique

Jean-Pierre Véran, « Pourquoi moi ? L'expérience des discriminations, François Dubet, Cousin Olivier Cousin, Eric Macé, Sandrine Rui », Revue internationale d'éducation de Sèvres [En ligne], 64 | décembre 2013, mis en ligne le 24 février 2014, consulté le 22 septembre 2020. URL : http:// journals.openedition.org/ries/3585; DOI : https://doi.org/10.4000/ries.3585

Ce document a été généré automatiquement le 22 septembre 2020.

(c) Tous droits réservés 


\title{
Pourquoi moi ? L'expérience des discriminations, François Dubet, Cousin Olivier Cousin, Eric Macé, Sandrine Rui
}

Seuil, 2013

\author{
Jean-Pierre Véran
}

\section{RÉFÉRENCE}

François Dubet, Cousin Olivier Cousin, Eric Macé, Sandrine Rui, Pourquoi moi ?

L'expérience des discriminations, Seuil, 2013, 360 p.

1 Comme l'indique le titre de l'ouvrage, c'est la parole même des sujets vivant l'expérience des discriminations qui est au cœur de cet ouvrage, puisque les auteurs ont pris le parti méthodologique de travailler à partir du langage des acteurs, recueilli au cours d'entretiens individuels, de débats collectifs ou d'interventions sociologiques. Dans le domaine de l'éducation, par exemple, des entretiens ont été conduits dans un lycée d'élite parisien, un lycée général accueillant nombre d'élèves issus de la "diversité » et dans un lycée professionnel majoritairement "réservé » à ces mêmes élèves ; un groupe de membres de l'éducation s'est réuni trois jours à Paris et a reçu des interlocuteurs variés. Il convient de préciser que cette étude porte exclusivement sur la France et son école, et que d'autres références, comme celle au "rêve américain ", ne sont abordées que pour éclairer la situation française. Si d'autres domaines ont été étudiés - la santé, la politique, le monde culturel et médiatique, l'éducation offre un axe de lecture important à trois titres au moins.

D'abord par sa mise en cause directe par ceux qui ont vécu ce que les auteurs appellent une " expérience totale de la discrimination », qui se traduit en trois figures majeures : la colère, l'écrasement de soi ou la réclusion. Les jeunes révoltés considèrent l'école 
comme vecteur de discrimination et de stigmatisation. Tout cela est voulu, selon eux, et l'échec scolaire relève de l'automaticité pour les non-blancs. Ceux qui, parmi eux, pourraient croire à la promesse fallacieuse d'égalité de l'école ne seraient que des «bouffons ", des « collabos ». Du côté des enseignants, un enseignant noir observe que, lorsqu'il annonce à ses collègues qu'il va se présenter au concours de personnel de direction, il suscite des sourires amusés, comme si le fait d'être noir était incompatible avec cette fonction. Du point de vue du parcours scolaire, de nombreux acteurs disent l'impression d'avoir été maltraités et livrés à eux-mêmes, d'avoir cumulé les inégalités, et d'avoir ainsi été « menés en bateau ».

3 Leur témoignage gagne à être mis en tension avec celui tenu par des responsables d'agences d'intérim qui expliquent que des emplois ne sont plus accessibles aux Noirs et aux Arabes qui ont été scolarisés en France, parce qu'ils n'en supporteraient pas la pénibilité : « même si vous avez été mauvais à l'école, vous avez appris des choses... on ne les trouve plus comme manœuvres, c'est normal, ils sont allés à l'école, ils ont un BTS, un bac pro.»

4 Ensuite, l'école est le lieu d'exercice des arts de la lutte et de l'esquive : on y esquive discrimination et stigmatisation en jouant de la conformité, voire de la sur-conformité, comme ces élèves filles de lycée professionnel se transformant en "garçons manqués ", ou comme ce professeur homosexuel qui ment à ses élèves pour ne pas enflammer la situation en défendant sa sexualité. Quant aux parents issus de l'immigration et désireux d'épargner l'automaticité de la relégation scolaire à leurs enfants, ils rusent avec la carte scolaire, comme les parents de la classe moyenne blanche.

5 Enfin, parce que la question de la discrimination à l'école touche la nature même de l'institution scolaire. L'école républicaine universaliste est censée produire des inégalités justes, fondées sur le classement, l'orientation d'élèves également instruits. Mais l'école est perçue comme discriminante, parce que le processus de tri n'est pas qu'individuel : il est aussi collectif, touchant des classes sociales et des territoires. L'apartheid scolaire est incompatible avec l'école universaliste, mais il existe. Si bien des inégalités ne sont pas imputables à l'école et si l'école accumule les dispositifs pour tenter d'y remédier (zones d'éducation prioritaires, internats d'excellence, etc.), on ne peut pas dire, comme certains cadres éducatifs, qu'il n'y aurait pas d'inégalité scolaire, seulement des inégalités sociales. L'école sanctuaire universaliste demeure une fiction.

6 L'école est alors plongée alors dans un insoluble dilemme : trahir son indifférence aux différences en prenant en compte la diversité des élèves ou demeurer une fiction égalitaire qui trompe de moins en moins son public. La racialisation des inégalités scolaires, le choc culturel entre la laïcité et les cultures venues des anciennes colonies peuvent-ils être évacués de la réflexion?

7 Entre les limites d'une priorité accordée exclusivement à l'égalité des citoyens et celles d'une priorité donnée aux différences, l'école, comme la République, ne devrait-elle pas choisir la priorité donnée à l'individu, perçu, non seulement comme égal mais encore comme semblable? Si la devise républicaine n'est pas complètement accomplie, c'est bien parce qu'au-delà de la liberté et de l'égalité, la fraternité est encore hors d'atteinte.

8 En quoi l'école pourrait-elle contribuer à développer la fraternité ? Sans doute en refusant les assignations identitaires qui stigmatisent et les assignations communautaires qui enferment, en permettant à chacun, en son sein, de choisir son identité. Cela signifierait, par exemple, de garantir le droit culturel de porter un signe 
religieux, lui-même soumis au droit premier de ne pas le porter. On le voit, la route est encore longue.

Le lecteur sera particulièrement intéressé par la réflexion, déjà conduite par François Dubet $^{1}$, sur l'égalité des places et l'égalité des chances, qui aboutit à ce constat que l'égalité des chances n'est pas toute la justice. Cette réflexion débouche naturellement sur une question : qu'est-ce que la nation, aujourd'hui ? On se souvient de l'intensité du débat en France sur l'identité nationale, notamment en 2011 et 2012, débat qui ne peut faire l'impasse sur la question du droit des minorités, à l'école comme dans toute la vie sociale.

Le lecteur appréciera tout autant les dix-sept pages de la bibliographie, qui convoque Tony Morrison, Philippe Roth, Nathalie Sarraute ou Richard Wright au même titre que des historiens, philosophes ou sociologues de l'éducation, et s'enrichit d'une filmographie de Lubitsch à Eastwood, en passant par Blake Edwards et Barry Levinson.

\section{NOTES}

1. Dubet, François, Les places et les chances, repenser la justice sociale, Paris, Seuil, La République des idées, 2010.

\section{INDEX}

Index géographique : France

\section{AUTEURS}

\section{JEAN-PIERRE VÉRAN}

Jean-Pierre Véran est inspecteur d'académie honoraire, formateur associé à l'Université Montpellier 2 où il enseigne notamment les politiques éducatives et la gouvernance des organisations scolaires. Membre du comité de rédaction de la Revue internationale d'éducation de Sèvres, il est co-auteur de : Le Conseiller principal d'éducation : de la vie scolaire à la politique éducative (2e édition, 2012) ; De l'emploi du temps aux emplois des temps : pour une approche globale du temps scolaire (2011), Berger-Levrault. 